\title{
Air Temperature, Humidity, and Leaf Age Affect Penetration of Urea Through Grapefruit Leaf Cuticles
}

\author{
Vladimir Orbović $\mathbf{c}^{1}$ and Diann Achor \\ Citrus Research and Education Center, University of Florida, Institute of Food and Agricultural \\ Sciences, 700 Experiment Station Road, Lake Alfred, FL 33850
}

Peter Petracek

Abbott Laboratories, 6131 RFD, Oakwood Road, Long Grove, IL 60047

\author{
James P. Syvertsen \\ Citrus Research and Education Center, University of Florida, Institute of Food and Agricultural \\ Sciences, 700 Experiment Station Road, Lake Alfred, FL 33850
}

Additional index words. $\mathrm{pH},{ }^{14} \mathrm{C}$, electron microscopy, waxes

\begin{abstract}
Effects of air temperature, relative humidity (RH), and leaf age on penetration of urea through isolated leaf cuticles of 'Marsh' grapefruit (Citrus $\times$ paradisi Macfad.) trees on 'Carrizo' citrange (C. sinensis L. Osbeck X Poncirus trifoliata (L.) Raf. rootstock were examined. Intact cuticles were obtained from adaxial surfaces of 'Marsh' grapefruit leaves of various ages. A finite dose diffusion system was used to follow movement of ${ }^{14} \mathrm{C}$-labeled urea from urea solution droplets across cuticles throughout a 4-day period. Within the first 4 to 6 hours after urea application, the rate of urea penetration increased as temperature increased from 19 to $28^{\circ} \mathrm{C}$, but there was no further increase at $38{ }^{\circ} \mathrm{C}$. Increasing relative humidity increased urea penetration at $28^{\circ} \mathrm{C}$ and $38^{\circ} \mathrm{C}$. Cuticle thickness, cuticle weight per area, and the contact angle of urea solution droplets increased as leaves aged. Cuticular permeability to urea decreased as leaf age increased from 3 to 7 weeks, but permeability increased in cuticles from leaves older than 9 weeks. Contact angles decreased with increased urea solution concentration on leaf surfaces that were 6 to 7 weeks old, but solution concentration had no effect on contact angle on cuticles from younger and older leaves. Changing urea solution pH from 8.0 to 4.0 could have an effect on the amount of urea penetrating the cuticle through the loss of urea from breakdown possibly due to hydrolysis. Results from this study define leaf age, environmental conditions, and formulation for maximum uptake of foliar-applied urea.
\end{abstract}

Urea is a foliar-applied, nitrogenous fertilizer valued for efficiency and low cost. An advantage of foliar application of $\mathrm{N}$ is that it reduces soil applications and thereby potentially reduces leaching of nitrate into groundwater (Council for Agricultural Science and Technology, 1985). Foliar applications of urea on Citrus L. sp. in Florida are common because of potential benefits beyond elevated leaf N concentration. Recently, Albrigo (1999) offered initial evidence about such effects of urea sprays on fruit yield in Citrus trees in Florida. There are reports describing leaf damage in Citrus sp., however, these are due to application at high urea concentrations (Bondada et al., 1995). Mechanisms of urea uptake into the leaves and subsequent action of urea are still not fully understood.

The leaf cuticle is the first barrier that urea must pass through on its way into leaves. Cuticles function in protection and waterproofing of all aerial plant organs (Martin and Juniper, 1970). The cuticle is composed of soluble cuticular lipids (SCL), which are embedded into the matrix of lipid polyester cutin (Jeffree, 1996). Detailed study of chloroform-soluble cuticular lipids from sour orange (C. aurantium L.) leaves identified fatty acids, primary alcohols, esters, and hydrocarbons as major constituents (Haas and Schönherr, 1979). Layers of cuticular waxes influence the wettability and permeability of Citrus leaf cuticles (Haas and

Received for publication 6 Mar. 2000. Accepted for publication 25 Sept. 2000 Florida Agricultural Experiment Station journal series R-07447. This work was funded in part by the Florida Department of Agriculture and Consumer Services, Florida Citrus Production Research Advisory Council. We acknowledge the assistance of Stephen Sax for statistical analysis. Also, we thank Megh Singh for letting us use the contact angle goniometer. The cost of publishing this paper was defrayed in part by the payment of page charges. Under postal regulations, this paper therefore must be hereby marked advertisement solely to indicate this fact. ${ }^{1}$ Corresponding author.
Schönherr, 1979; Jeffree, 1996). Both quantity and chemistry of cuticular waxes change throughout the development of Citrus leaves (Freeman et al., 1979).

There have been studies of cuticular penetration and foliar uptake of plant growth regulators such as auxins (Black et al., 1995; Greene and Bukovac, 1971; Norris and Bukovac, 1969; Shafer et al., 1988), gibberellins (Knoche and Bukovac, 1999; Knoche et al., 1992), and cytokinins (Petracek et al., 1998). Effects of foliar application of urea on grasses (Bowman and Paul, 1992; Wesely et al., 1987) and fruit trees have been studied (Ali and Lovatt, 1992; Rabe, 1994) but mechanisms of urea uptake and effects of environmental variables on penetration rates were not described. Total uptake of urea through abaxial and adaxial surfaces of Citrus leaves was similar 24 to $30 \mathrm{~h}$ after application (Impey and Jones, 1960). Lea-Cox and Syvertsen (1995) reported that the uptake of urea into the leaves of 'Redblush' grapefruit (Citrus $\times$ paradisi Macfad.) was dependent upon the total $\mathrm{N}$ content of the shoot. Studies of cuticular penetration of urea were performed in some species (Knoche et al., 1994; Yamada et al., 1965) but none of them dealt with the unique waxy cuticles of Citrus.

Therefore, our goal was to determine how different temperature, relative humidity $(\mathrm{RH})$, and leaf age affect urea penetration through Citrus cuticles and to define a set of conditions under which penetration of urea would be maximized.

\section{Materials and Methods}

Plant material. Leaves of different ages were harvested from ten 15-year-old 'Marsh' grapefruit (Citrus $\times$ paradisi) trees on 'Carrizo' citrange (C. sinensis $x$ Poncirus trifoliata) rootstock. Trees were part of an unsprayed orchard at the University of 
Florida, Citrus Research and Education Center, Lake Alfred. Harvested leaves were the product of the late summer flush (September to October 1998) and early spring flush (February to March 1999) and were all from the south-facing portion of the canopy at a height of 1 to $2 \mathrm{~m}$. Although harvested leaves came from 10 different trees, we did not test inter-tree variability.

Cuticle isolation. Circular disks ( $15 \mathrm{~mm}$ in diameter) without major veins were removed with a cork borer from leaves. Disks were soaked in an digestion solution of Na-citrate buffer $(50 \mathrm{~mm})$ adjusted to $\mathrm{pH} 4.0$ to which $4 \%(\mathrm{w} / \mathrm{v})$ of pectinase and $0.4 \%$ (w/v) of cellulase were added (Yamada et al., 1964). To prevent the growth of microorganisms, $1 \mathrm{mmol} \cdot \mathrm{L}^{-1}$ of sodium azide was added to the solution.

Incubation of leaf disks in the digestion solution lasted for $4 \mathrm{~d}$ at room temperature $\left(23^{\circ} \mathrm{C}\right)$. Throughout incubation, disks were exposed intermittently to a vacuum to facilitate infiltration of enzymes into the leaf tissue. After digestion of internal leaf tissue, cuticles were gently washed away from the internal tissue. Cellular debris remaining on cuticles was digested a second time in fresh enzymatic solution overnight and gently rinsed for 2 to $4 \mathrm{~h}$ with running distilled water. After rinsing, cuticles were extracted from the water on a piece of teflon and allowed to air dry. Adaxial cuticles were selected under the microscope for lack of stomata. Cuticles were tested for leaks by using a slight hydrostatic pressure (Petracek et al., 1998).

Measurement of Cuticular Penetration. Cuticular penetration of urea was measured using a finite dose diffusion system (Petracek et al., 1998) that allowed repeated sampling of solution in contact with the cuticle. Radioactively labeled ${ }^{14} \mathrm{C}$-urea (specific activity $=2.05 \times 10^{9} \mathrm{~Bq} \cdot \mathrm{mmol}^{-1}$, purity $\geq 98 \%$, Sigma, St. Louis, Mo.), at $2.8 \mathrm{mmol} \cdot \mathrm{L}^{-1}$, was deposited onto the outer surface of a cuticle in three $1-\mu \mathrm{L}$ droplets. This represented the activity of $\approx 60$ $\times 10^{6} \mathrm{~Bq}$. Following urea deposition, $100 \mu \mathrm{L}$ subsamples were taken from the reservoir below the cuticle in specific time increments, added to the $4 \mathrm{~mL}$ of scintillation liquid (SX 18-4, Fisher Scientific, St. Louis, Mo.) and counted in the liquid scintillation counter (LS 6000SC, Beckman Coulter Inc., Fullerton, Calif.). The sample

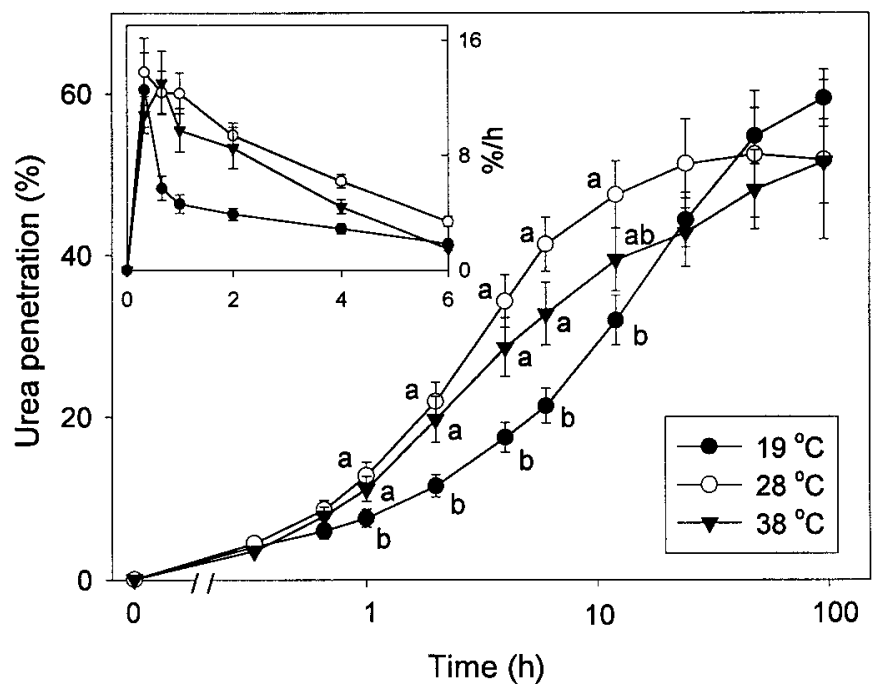

Fig. 1. Effect of temperature on penetration of urea through the (>12 weeks old) isolated 'Marsh' grapefruit leaf cuticles. (Inset: penetration rate within the first $6 \mathrm{~h}$; Y-axis shows percentage of applied urea per hour). Data are means \pm SE. Within each sampling time, means labeled with the same letter (or no letters) are not significantly different according to Duncan's multiple range test $(P<0.05)$. volume was replaced with water. Ambient temperature and RH within a growth room were controlled using a combination of a refrigerated air conditioner, electric heater, dehumidifier, and vaporizer. Dataloggers (HOBO, Onset Computer Corp., Bourne, Mass.) were used to record air temperature and $\mathrm{RH}$ within the growth room. Temperature set points were: $19 \pm 1.5^{\circ} \mathrm{C} ; 28 \pm 2{ }^{\circ} \mathrm{C}$; and $38 \pm 2{ }^{\circ} \mathrm{C}$. For the purposes of different experiments, RH was maintained in the ranges of: $5 \%$ to $20 \%, 20 \%$ to $35 \%, 35 \%$ to $50 \%$, and $50 \%$ to $75 \%$. Lowest range of humidity included levels (20\% $\mathrm{RH})$ that are not uncommon during dry spring months (March) in Florida. At the end of all experiments described above, cuticles were dried for $10 \mathrm{~min}$, removed from the cuticle holder and radio-assayed for the presence of urea.

Measurement of CONTACT ANGLES. Individual dried cuticles of different ages were positioned on a teflon slide by using vacuum grease, which was applied to the edges of the cuticles. Two to three $2-\mu \mathrm{L}$ droplets of test solutions of zero (control) to $2.8 \mathrm{~mol} \cdot \mathrm{L}^{-1}$ of urea were deposited onto the cuticle, and contact angles were measured with a Contact Angle Goniometer (Rame-hart, Inc., Mountain Lakes, N.J.). Contact angles on two sides of each droplet were measured. Number of replications for each data point in these experiments was 16 to 25 . When contact angles were measured on a teflon slide, droplets were deposited directly onto it.

MEASUREMENT OF UREA BREAKDOWN AT DIFFERENT PH. Na-citrate buffer solution $(50 \mathrm{~mm}$ ) was adjusted (with $\mathrm{NaOH}$ ) to provide a range of $\mathrm{pH}$ from 4.0 to 8.0. Four milliliters of each solution of different acidity were put into open glass vials and placed in the fume hood. Into each vial, $3 \mu \mathrm{L}$ of ${ }^{14} \mathrm{C}$ labeled urea (activity $\approx 60 \times 10^{6} \mathrm{~Bq}$ ) was added and samples taken from the vial in specific time intervals over $144 \mathrm{~h}$. The amount of radioactivity left in the vials was calculated from the number of counts measured by the scintillation counter for each sample. These experiments were performed at 23 $\pm 2{ }^{\circ} \mathrm{C}$ and $20 \%$ to $35 \% \mathrm{RH}$.

Electron MICroscopy. For transmission electron microscopy (TEM), digested cuticles were fixed in $1 \%$ potassium permanganate dissolved in $0.1 \mathrm{M}$ potassium phosphate buffer at $\mathrm{pH} 7.2$ for 1 to $2 \mathrm{~h}$, followed by dehydration in acetone. The samples were

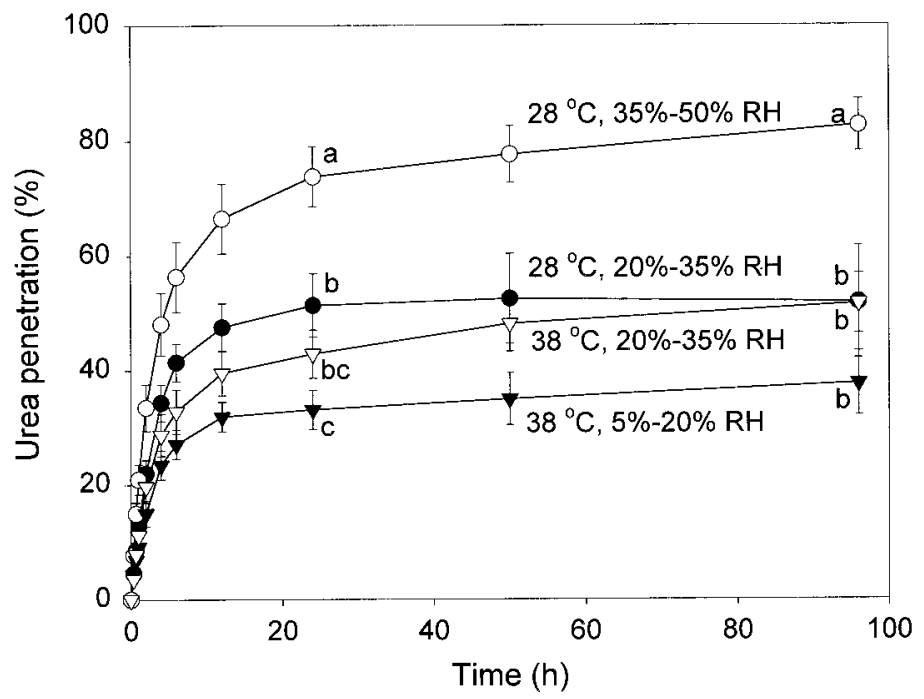

Fig. 2. Effect of RH ranges on penetration of urea through isolated 'Marsh' grapefruit leaf cuticles $(>12$ weeks old). Data are means \pm SE. Statistical analyses were done within the $24 \mathrm{~h}$ and $96 \mathrm{~h}$ sampling times. Means labeled with the same letter are not significantly different according to Duncan's multiple range test $(P<0.05)$. 
then infiltrated and embedded in Spurr's resin (Spurr, 1969), thin sectioned with an LKB Huxley Ultramicrotome (LKB Produkter, Bromma, Sweden), and stained using uranyl acetate (Stempak and Ward, 1964) and lead citrate (Reynolds, 1963). Observations were made and photographed with a Philips 201 (Philips Corp., Eindhoven, The Netherlands) transmission electron microscope.

For scanning electron microscopy (SEM), small $\left(5 \mathrm{~mm}^{2}\right)$ leaf tissue samples were cut from the midlamina area of fully expanded, mature, 2-month-old leaves. These samples received a droplet of urea solution on the adaxial surface. After deposition of urea, leaf samples were either left under the conditions of low humidity $\left(\mathrm{RH}=20 \%\right.$ to $35 \%$ at $23 \pm 2^{\circ} \mathrm{C}$ ) or very high humidity ( $\mathrm{RH}=80 \%$ to $100 \%$ at $23 \pm 2{ }^{\circ} \mathrm{C}$ ) for $24 \mathrm{~h}$. Samples were then attached to microscope metal stubs by using double-sticky copper tape and placed individually in small baskets. These baskets were plunged into liquid $\mathrm{N}$ and samples were freeze-dried using a modified version of the method described by Katoh and Matsumoto (1980), omitting the acetonitrile step. After drying, the leaf samples were remounted on different stubs, coated lightly with gold/palladium (Katoh and Matsumoto, 1980), and examined with a Hitachi S530 (Hitachi Ltd., Tokyo, Japan) scanning electron microscope.

Data ANAlyses. All data presented are means of at least 10 replications (15 to 26 replications for contact angle measurements) \pm SE. Each experiment was conducted at least twice, and the data were pooled for analyses. Data were analyzed using analysis of variance procedures for a completely randomized design (SAS Institute, Cary, N.C.) with environmental conditions and leaf age as independent variables. Significant differences between treatment means were determined using Duncan's multiple range test at $P<0.05$.

\section{Results}

Under almost all experimental conditions, penetration of urea was complete within the first 12 to $24 \mathrm{~h}$ after application and only insignificant amounts of urea diffused through the cuticles during the subsequent $3.5 \mathrm{~d}$ (Figs. 1 and 2). Increasing temperature from 19 to $28^{\circ} \mathrm{C}$ resulted in an increase of total amount of urea which diffused through the cuticles within the period between the first $1 \mathrm{~h}$ and $24 \mathrm{~h}$ (Fig. 1). An increase in temperature from 28 to $38^{\circ} \mathrm{C}$ did not increase the amount of urea penetrating through the cuticle. When compared to $19{ }^{\circ} \mathrm{C}$, the amount of urea passing through the cuticle at $38^{\circ} \mathrm{C}$ was higher in the period between $1 \mathrm{~h}$ and $12 \mathrm{~h}$ following application. Total amount of urea that diffused through the cuticles at $28{ }^{\circ} \mathrm{C}$ reached a maximum of about $50 \%$ $24 \mathrm{~h}$ after application. The time required for the amount of urea penetrated through the cuticles to reach the same level was at least twice as long at $19^{\circ} \mathrm{C}(48 \mathrm{~h})$ and about four times longer at $38^{\circ} \mathrm{C}$ $(96 \mathrm{~h})$. At $19^{\circ} \mathrm{C}$, penetration rate decreased after the initial $20 \mathrm{~min}$
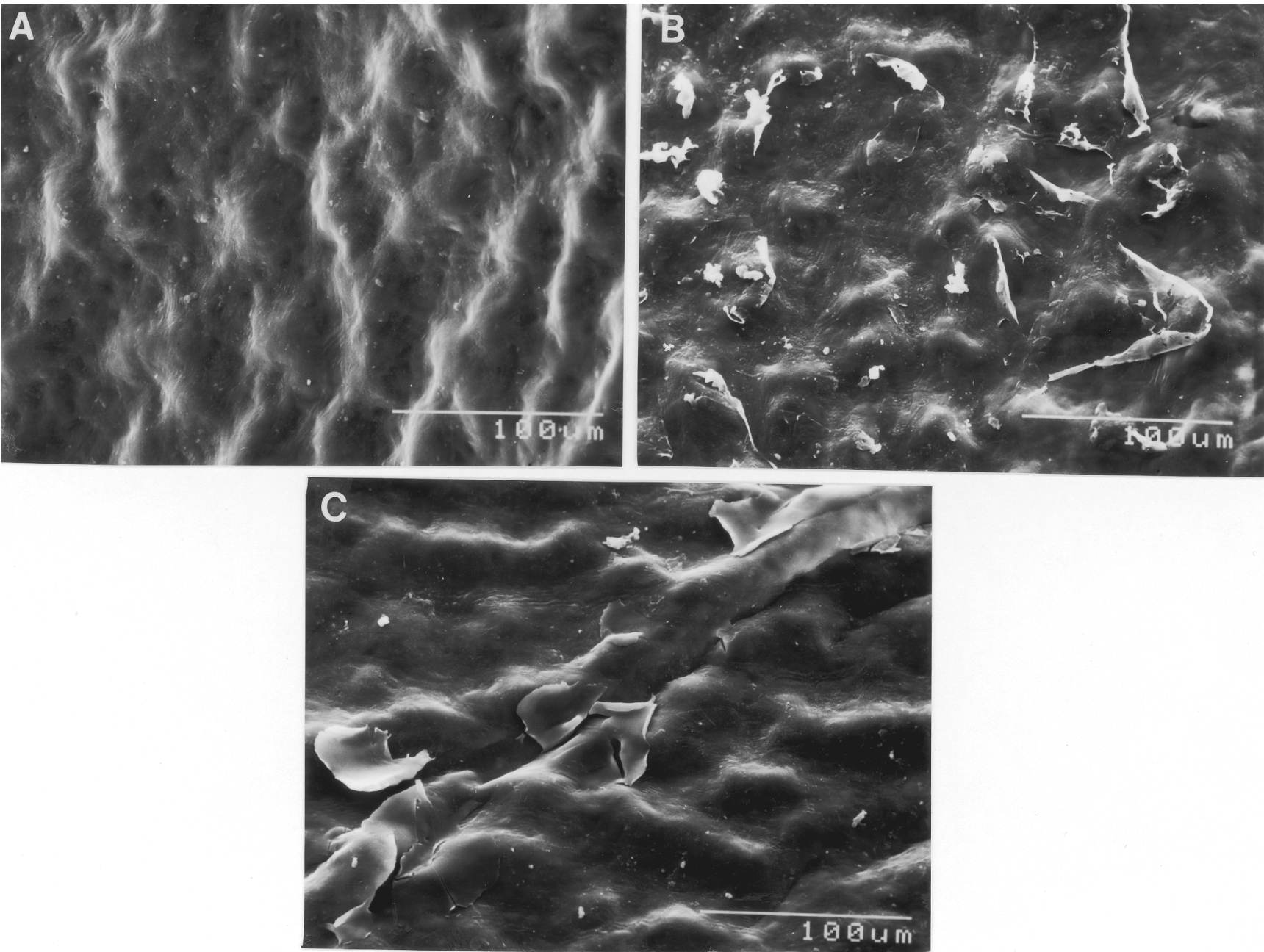

Fig. 3. Scanning electron micrographs of the surface of 5- to 6-week-old 'Marsh' grapefruit leaves $24 \mathrm{~h}$ after (A) no urea application and kept at low RH (20\% to $35 \%$ ), (B) application of droplets of urea at low RH (20\% to 35\%), and (C) application of droplets of urea at high RH (80\% to $100 \%)$. 
increase and reached the level of $\approx 1 \% / \mathrm{h} 6 \mathrm{~h}$ after urea application. Penetration rate at $28^{\circ} \mathrm{C}$ and $38^{\circ} \mathrm{C}$ increased sharply for the first 20 to $40 \mathrm{~min}$ to a level of $\approx 12 \% / \mathrm{h}$ and then decreased slowly thereafter (Fig. 1 inset). Enhancement of penetration rate as a result of temperature increase from 19 to $28^{\circ} \mathrm{C}$ continued for the first $4 \mathrm{~h}$.

Cuticular penetration of urea was enhanced with an increase in $\mathrm{RH}$ at both 28 and $38{ }^{\circ} \mathrm{C}$. At $28^{\circ} \mathrm{C}$, urea penetration was $50 \%$ greater for $35 \%$ to $50 \% \mathrm{RH}$ than for $20 \%$ to $35 \% \mathrm{RH}$ by $24 \mathrm{~h}$ and continued until $96 \mathrm{~h}$ after application (Fig. 2). Increasing RH from $5 \%$ to $20 \%$ to $20 \%$ to $35 \%$ at $38^{\circ} \mathrm{C}$ yielded a similar although not statistically significant increase in urea penetration.

There were no signs of urea deposits on control leaf samples (Fig. 3A). As water evaporated, urea left a microscopic layer of a solid deposit throughout the area where a droplet was applied on the leaf surface (Fig. 3B and C). At 20\% to 35\% RH the droplet dried rapidly, and the deposit was thin. The resulting film of urea became detached and curled away in many places (Fig. 3B). Extended curling of detached pieces of urea residue resulted in irregularly shaped clumps (Fig. 3B). High RH (80\% to 100\%) allowed for the longer persistence of a layer of urea on the leaf surface because the droplet did not dry within $24 \mathrm{~h}$. Under these conditions, the urea layer appeared thicker and well attached to the leaf surface (Fig. $3 \mathrm{C})$. These deposits were undoubtedly urea and not epicuticular waxes since SEM of urea droplets on glass cover slips (not illustrated) appeared similar to deposits in Fig. 3C.

Cuticles from expanding ( 3 to 4 weeks old) leaves had a permeability to urea similar to cuticles from fully expanded but not yet fully thickened leaves ( 9 to 10 weeks old) between 12 to $96 \mathrm{~h}$ after urea application (Fig. 4). Cuticles from recently fully expanded leaves ( 6 to 7 weeks old) had permeability to urea lower than oldest ( $>12$ weeks old) cuticles but similar to youngest ( 3 to 4 weeks old) cuticles throughout the $96 \mathrm{~h}$ period after urea application. We found the highest permeability to urea in cuticles from the oldest leaves (>12 weeks old; Fig. 4.)

SEM revealed a reticulate morphology for the young cuticles (Fig. 5A and B). Cuticles from the oldest leaves appeared amorphous (Fig. 5C). There were no apparent structural damage or

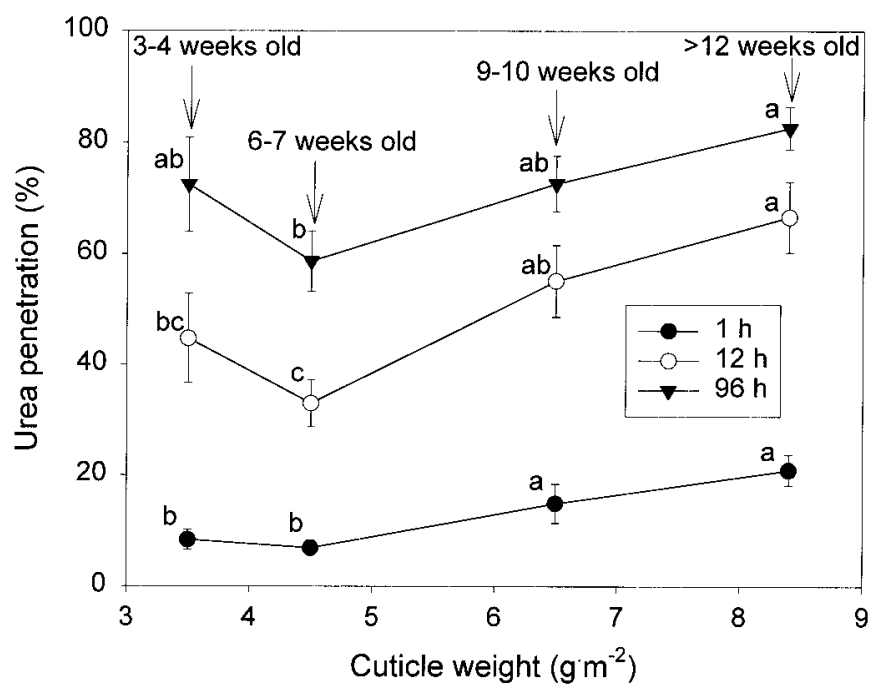

Fig. 4. Effect of leaf age on total amount of urea penetrating through isolated 'Marsh' grapefruit leaf cuticles within three sampling times. Experiments were run at $28{ }^{\circ} \mathrm{C}$ and $35 \%$ to $50 \% \mathrm{RH}$. Data are means \pm sE. Within sampling time, different letters denote significant differences according to Duncan's multiple range test $(P<0.05)$. alterations that might have been related to the process of cuticle isolation or age. Very young cuticles were the thinnest whereas the old cuticles were the thickest (Fig. 5).
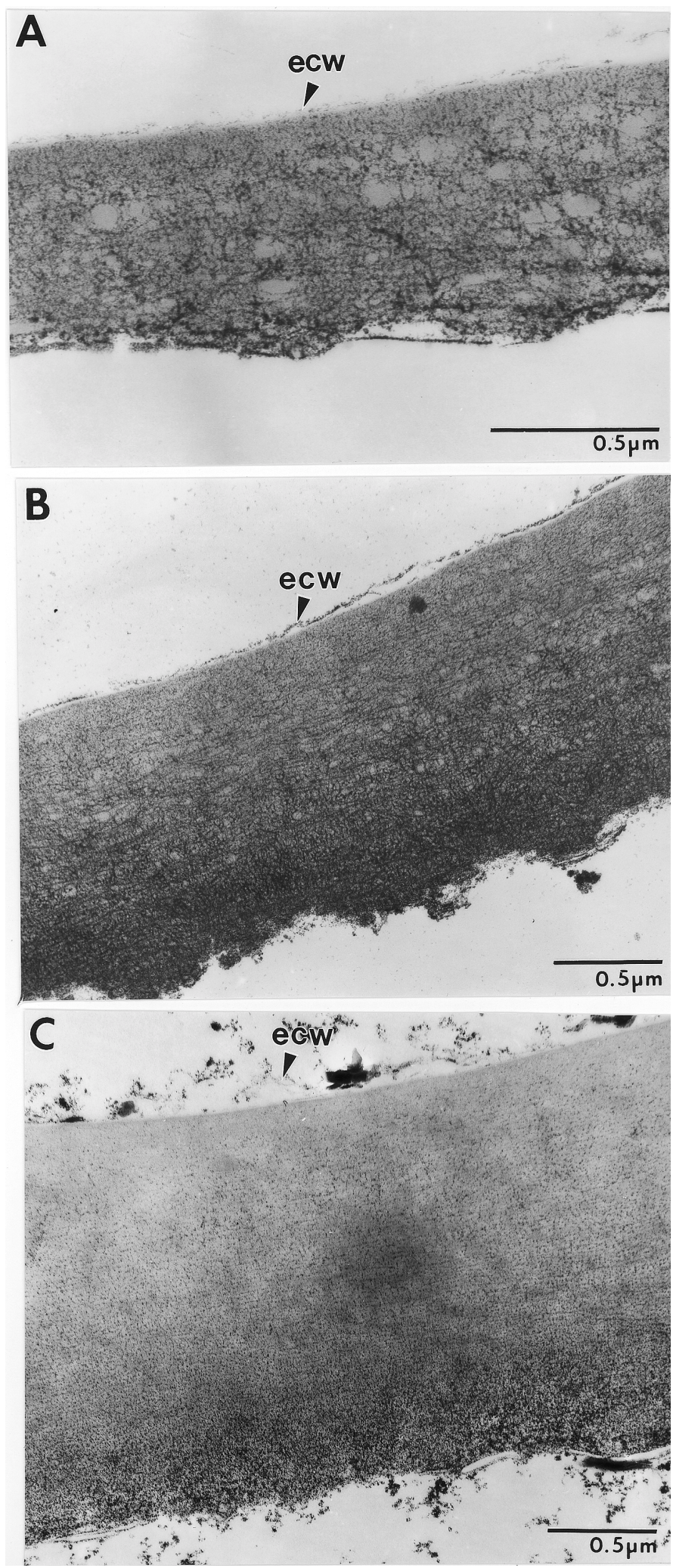

Fig. 5. Transverse sections through the cuticles of field-grown 'Marsh' grapefruit leaves (A) 3 to 4 weeks old, (B) 6 to 7 weeks old, and (C) $>12$-week-old leaves. Epicuticular wax $=\mathrm{ecw}$. 


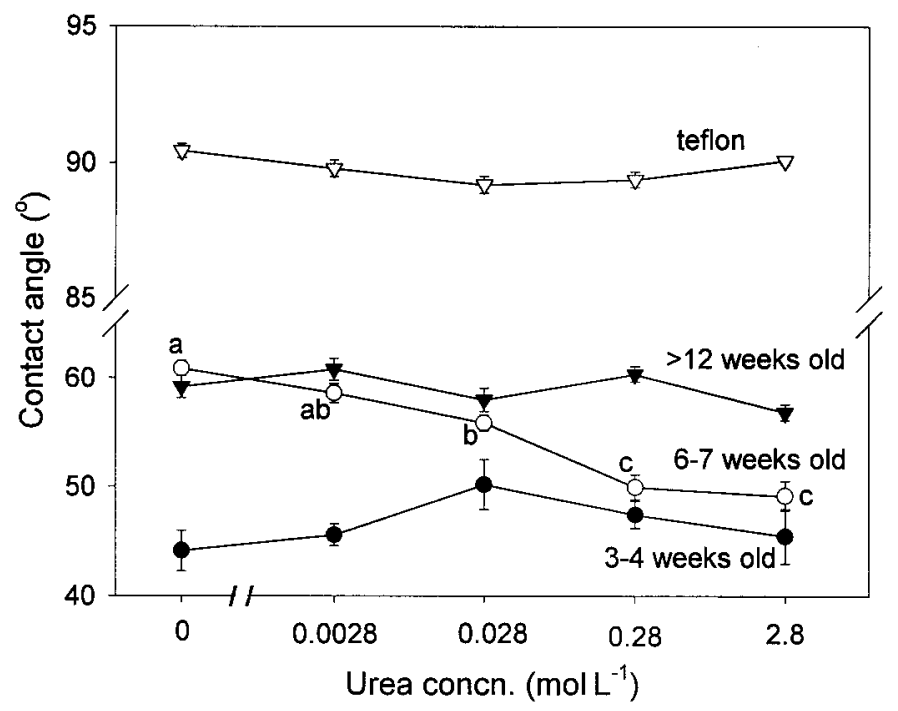

Fig. 6. Effect of urea concentration and leaf age of 'Marsh' grapefruit on contact angles of $2-\mu \mathrm{L}$ droplets. Data are means \pm sE. Within a leaf age, means differed over concentrations only for leaves 6 to 7 weeks old according to Duncan's multiple range test $(P<0.05)$.

Contact angles of $2-\mu \mathrm{L}$ droplets deposited on cuticles $>12$ weeks old did not change with urea concentration (Fig. 6). Although angles were $\approx 15^{\circ}$ smaller on cuticles from youngest leaves than on old cuticles, angles did not change with urea concentration. However, increasing urea to $>0.028 \mathrm{~mol} \cdot \mathrm{L}^{-1} \mathrm{de}-$ creased the contact angles of droplets applied to cuticles that were 6 to 7 weeks old (Fig. 6).

Urea loss at various $\mathrm{pH}$ was measured as the loss of ${ }^{14} \mathrm{C}$ from the solution. Because loss of ${ }^{14} \mathrm{C}$ could have resulted only from volatilization of $\mathrm{CO}_{2}$ as a product of urea breakdown, we can say that we indirectly measured urea breakdown at different acidities. At $\mathrm{pH} 4.0$ and $\mathrm{pH} 5.0$, urea breakdown approached $100 \%$ within $24 \mathrm{~h}$ (Fig. 7). Urea breakdown occurred at almost identical kinetics at $\mathrm{pH} 6.0$ and $\mathrm{pH} 7.0 ; \approx 20 \%$ of urea was broken down within $1 \mathrm{~d}$ and complete breakdown required 2 to $4 \mathrm{~d}$. Breakdown of urea was the slowest at $\mathrm{pH} 8.0 ; \approx 20 \%$ broke down within $2 \mathrm{~d}$ and up to $75 \%$ within $6 \mathrm{~d}$ (Fig. 7).

\section{Discussion}

Most urea penetrated the cuticle within the first 12 to $24 \mathrm{~h}$ after application (Figs. 1 and 2). When penetration of N-benzyladenine through the isolated cuticles of tomato (Lycopersicon esculentum Mill.) fruit was tested, diffusion of this compound continued at a slow rate for more than $10 \mathrm{~d}$ after application (Bukovac and Petracek, 1993), and penetration of naphthaleneacetic acid through isolated cuticles of pear (Pyrus communis L.) leaves was linear during a period of $16 \mathrm{~d}$ (Norris and Bukovac, 1969). Yamada et al. (1965) reported nonlinear penetration of urea when applied at high concentration to tomato fruit cuticles and suggested that urea may affect its own uptake by changing cuticular permeability. However, Knoche et al. (1994) found a near-linear trend of penetration of urea for at least $7 \mathrm{~h}$ after the application to tomato fruit cuticles and refuted Yamada's suggestions. The similarities of initial penetration rates at $19^{\circ} \mathrm{C}, 28^{\circ} \mathrm{C}$, and $38^{\circ} \mathrm{C}$ and then up to $2 \mathrm{~h}$ at $28^{\circ} \mathrm{C}$ and $38^{\circ} \mathrm{C}$ (Fig. 1), did not suggest an ability of urea to alter permeability of grapefruit leaf cuticles.

Foliar uptake and cuticular penetration of applied substances can increase with temperature (Baur and Schönherr, 1995; Black et al., 1995;

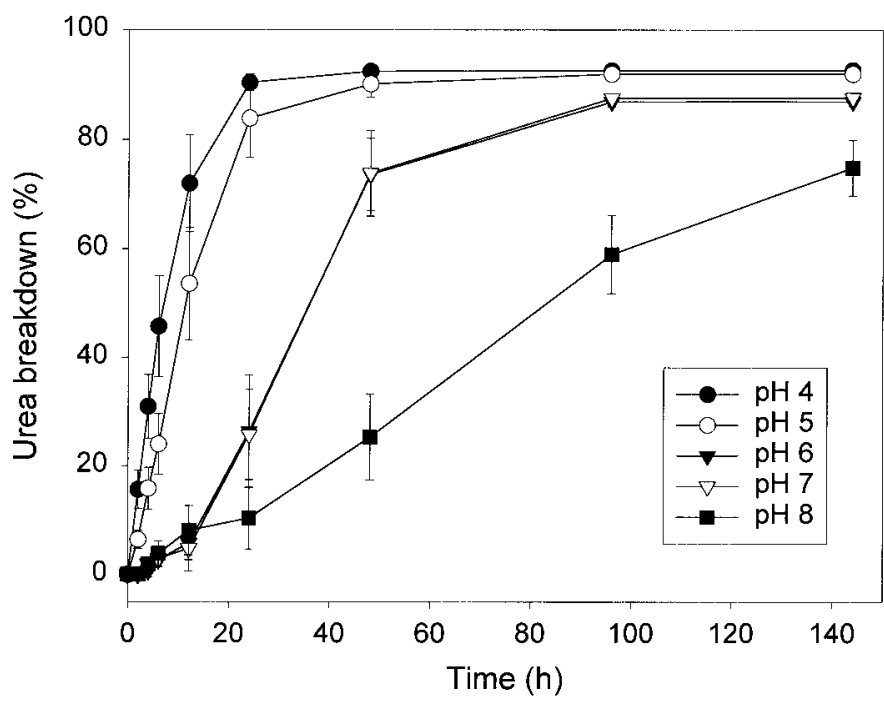

Fig. 7. Effect of solution $\mathrm{pH}$ on the breakdown of urea as estimated from loss of ${ }^{14} \mathrm{C}$ over a $144 \mathrm{~h}$ period. Data are means $\pm \mathrm{SE}$.

Greene and Bukovac, 1971; Knoche et al., 1994; Norris and Bukovac, 1969). We also found higher penetration of urea at $28{ }^{\circ} \mathrm{C}$ than at $19{ }^{\circ} \mathrm{C}$ within the first $12 \mathrm{~h}$ (Fig. 1). Increase in temperature from $28^{\circ} \mathrm{C}$ to $38^{\circ} \mathrm{C}$ did not affect urea penetration. We have three possible explanations for these findings. First, cuticular permeability $(\mathrm{P})$ is a product of a diffusion coefficient (D) and a partitioning coefficient $(\mathrm{K}): \mathrm{P}=\mathrm{D} \times \mathrm{K}$.

Diffusion typically increases with temperature, but partitioning can decrease with increasing temperatures due to changes in solubility resulting from a phase transition in the cuticle (Shafer et al., 1988). The phase transition takes place in cuticles at specific temperatures. Eckl and Gruler (1980) reported that at $>37^{\circ} \mathrm{C}$, parts of Citrus cuticles become fluid. They suggested that the phase transition was related to the soluble cuticular lipids which are considered the determining factor for permeability of the cuticle (Haas and Schönherr, 1979).

A second explanation for our findings is related to the measured decrease in apparent drying time of droplets with the increase in temperature. With the decrease in $\mathrm{RH}$, droplet drying time decreased from $25 \mathrm{~min}$ at $19^{\circ} \mathrm{C}$ to $11 \mathrm{~min}$ at $38^{\circ} \mathrm{C}$. Fast evaporation of water from droplets at $38{ }^{\circ} \mathrm{C}(5 \%$ to $20 \% \mathrm{RH})$ probably promoted volatilization of ammonia from urea by concentrating urea and increasing the $\mathrm{pH}$ in the remaining deposit (Reynolds and Wolf, 1987; Wesely et al., 1987). At $28^{\circ} \mathrm{C}$, RH was higher and evaporation was slower, which, together with beneficial deposition of urea (Fig. 3C), likely enhanced penetration. A third explanation relates to the rapidity of urea breakdown at high temperatures. With an increase in temperature, activity of urease is enhanced (Yadav et al., 1987) which could have resulted in less residual urea to diffuse across the cuticle.

After urea droplets are deposited onto the cuticle, penetration through the cuticle and the breakdown of urea begin at the same time. Only $1 \%$ to $3 \%$ of the initial radioactivity remained associated with the cuticles $4 \mathrm{~d}$ after urea application in all the treatments. After accounting for the amount that penetrated, this means that the breakdown and loss of urea after $4 \mathrm{~d}$ was between $15 \%$ for the most-favorable and $60 \%$ for the least-favorable conditions for penetration (Fig. 2). Urea breakdown reported after foliar application to ryegrass turf (Lolium perenne L.) and Kentucky Bluegrass (Poa pratensis L.) was $\approx 30 \%$ and $31 \%$ to 
$35 \%$ after 2 and 4 d, respectively (Bowman and Paul, 1992; Wesely et al., 1987). Losses from soil application of urea can be as high as $60 \%$ depending on the environment (Reynolds and Wolf, 1987). It is generally believed that the enzyme urease is responsible for breakdown of foliar-applied urea to $\mathrm{CO}_{2}$ and ammonia (Ferguson et al., 1984). The activity of soil urease is promoted by high RH (Reynolds and Wolf, 1987; Wesely et al., 1987; Yadav et al., 1987). Thus, we should have found higher urea penetration at low RH, because urease activity should have been low. On the contrary, we found that higher amounts of urea penetrated the cuticles under higher humidity (Fig. 2). There are two possible reasons for this.

First, a thick, well-attached layer of urea found on the leaf surface at high RH (Fig. 3C) may allow the microchannels within the cuticle to stay well hydrated and create a steep concentration gradient across the cuticle, thereby providing favorable conditions for urea diffusion. Schönherr and Schmidt (1979) proposed the existence of channels traversing the cuticle. When hydrated, these channels represent a way for water molecules to move across the cuticle, and urea molecules could move with them as well. Under the conditions of low RH, the layer of urea on the leaf surface was very thin and it detached from the leaf surface in many places (Fig. 3B). On a typical dry day during winter in Florida, minimum humidity can fall to $<20 \%$.

The second reason for higher urea penetration at high $\mathrm{RH}$ may be that the pool of urea deposited onto the cuticle where it could be the substrate for urease, was being depleted by diffusion into the experimental cell. It has been reported that urease activity has a lag phase of $24 \mathrm{~h}$ (Reynolds and Wolf, 1987), and within that time most of the urea already penetrated through the cuticles. We have not examined cuticles for the presence of urease activity.

When growers spray urea onto Citrus trees, they often mix it with other active compounds and adjuvants, some of which may change the chemistry of the solution mixture. Although we did not measure the direct effect of solution $\mathrm{pH}$ on cuticular penetration, we examined the stability of urea in the solutions of different $\mathrm{pH}$ with emphasis on acidic conditions. The breakdown of urea in droplets already applied onto leaves would, therefore, indirectly affect urea penetration through the cuticles. At low $\mathrm{pH}$, urea breakdown proceeded very rapidly and was complete within 24 h (Fig. 7). Acidity increases the likelihood of urea degradation to ammonia and carbamate by hydrolysis (Morrison and Boyd, 1974). The fact that the breakdown of urea slowed as $\mathrm{pH}$ values approached neutrality, suggests a detrimental effect of acidity on urea (Fig. 7).

Cuticles grow and develop as leaves expand and thickness of the cuticles of grapefruit increased with age (Fig. 5). However, permeability did not exhibit the same trend. Within the first 6 to 7 weeks, permeability of cuticles decreased while the thickness increased (Fig. 4). As the cuticle thickens, more and more lipids are embedded into the developing cutin matrix resulting in decreased permeability of cuticles which are 6 to 7 weeks old compared to those which are 3 to 4 weeks of age (Jeffree, 1996; Fig. 4). Cuticles $>12$ weeks old were more permeable than those which are 6 to 7 weeks old (Fig. 4). Although all cuticles passed a leak test, we examined the structural integrity of isolated cuticles to exclude the possibility that physical damage might have been responsible for this increase in permeability. There was no apparent damage found on TEM sections of any cuticles. The appearance of grapefruit leaf cuticles was very similar to the leaf and fruit cuticles from other Citrus sp. (Fig. 5; Espelie et al., 1980).
There is good evidence for the existence of polar pores in the polymer matrix of Citrus cuticles. Their radii were estimated to be $\approx 0.46 \mathrm{~nm}$, which is sufficient to allow the passage of urea molecules with radii of $0.26 \mathrm{~nm}$ (Schönherr, 1976). The existence of channels in cuticles depends on fluidity and arrangement of SCL within polymer matrix. Fluid SCL can be positioned in polymer matrix in an unorganized manner (as blobs), and can either cover or plug some, but not all of the pores existing in the polymer matrix (Schönherr and Schmidt, 1979). Channels may also result from a surface parallel arrangement of SCL such that their polar groups face each other and form pores or plane structures in the direction of transport (Schönherr and Schmidt, 1979). This idea would require highly regular organization of long chains of SCL. We suggest that as cuticles become fully developed and start aging they lose fluidity. As a consequence, their SCL become better organized within the polymer matrix and assume more stable positions, thereby allowing the establishment of more microchannels proposed by Schönherr and Schmidt (1979). This in turn, would result in higher permeability to water and urea. Eckl and Gruler (1980) showed that fully developed cuticles assume a rather rigid structure under specific environmental conditions, offering support for our idea.

The spread of a droplet and its contact angle with the cuticle are dependent on the epicuticular wax that develops as the cuticle matures as well as on the polarity of the leaf surface due to the chemical composition of waxes (Martin and Juniper, 1970). Larger contact angles of droplets of water were measured on older cuticles than on the younger cuticles (Fig. 6). The amount of epicuticular waxes increases with the age of Citrus leaves and, as a result, wettability decreases (B. Bondada, personal communication). The reason for the unique effect of high concentrations of urea decreasing the size of contact angles of droplets on leaves which are 6 to 7 weeks old is not clear. Freeman et al., (1979) reported that throughout development of Navel orange ( $C$. sinensis L.) leaves, the proportion of primary alcohols within the pool of total waxes changes, rendering the cuticle less hydrophobic. When leaves of grapefruit are 6 to 7 weeks old, the chemical composition of their epicuticular waxes may enhance spreading of urea at higher concentration. Despite their possible composition change, cuticles can maintain their low wettability (expressed as a high contact angle in Fig. 6) due to the quantity and pattern of wax distribution. For 5-month-old Navel orange leaves, epicuticular wax coverage can crack leaving the cuticular surface exposed beneath crevices (Freeman et al., 1979). This would allow droplets applied onto leaves to have large contact angles and still get into direct contact with cuticles which may be the reason for the high urea penetration through the cuticles from oldest leaves we used in this study (Fig. 4). Because epicuticular waxes are difficult to remove from cuticles without affecting intracuticular waxes, it is extremely difficult to examine their direct effect on urea penetration.

In contrast to other species where urea uptake is greater through abaxial than adaxial surface of leaves (Cook and Boynton, 1952; Freiberg and Payne, 1957; Klein and Weinbaum, 1985) our data support those of Impey and Jones (1960) who found that absorption of $\mathrm{N}$ was similar through abaxial or adaxial surface of Citrus leaves 24 to $30 \mathrm{~h}$ after urea application. Similar to our results, by $30 \mathrm{~h}$ after urea application, Impey and Jones found that similar amounts of urea were absorbed by young and mature leaves (Fig. 4).

Cuticular penetration of urea depends on environmental factors and on characteristics of the cuticle itself. Our results suggest 
that urea sprays of Citrus sp. trees should be done at 25 to $31^{\circ} \mathrm{C}$ and high $\mathrm{RH}$ to achieve maximum penetration. Thus, spraying at night when diurnal temperature is low and humidity is high is an appropriate practice to increase urea penetration. Citrus sp. trees have mature leaves with relatively high permeability to urea present in the canopy throughout the year. Consequently, penetration of urea should be facilitated regardless of the season. Although newly developed leaves are slightly less permeable to urea, it should be noted that young leaves are more sensitive to urea phytotoxicity than mature leaves (Lea-Cox and Syvertsen, 1995) so rates should not be increased when young flush is present. Urea spray solution should be kept at $\mathrm{pH} 7.0$ to $\mathrm{pH} 8.0$ to prevent urea loss from breakdown during preparation and spraying.

\section{Literature Cited}

Albrigo, L.G. 1999. Effects of foliar application of urea or Nutriphite on flowering and yields of Valencia orange trees. Proc. Fla. State Hort. Soc. 112:1-5.

Ali A.G. and C.J. Lovatt. 1992. Winter applications of foliar urea. Citrograph 78:7-9.

Baur, P. and J. Schönerr. 1995. Temperature dependence of the diffusion of organic compounds across plant cuticles. Chemosphere 30:13311340.

Black, B.L., P.D. Petracek, and M.J. Bukovac. 1995. The effect of temperature on uptake of NAA by Redchief 'Delicious' apple leaves. J. Amer. Soc. Hort. Sci. 120:441-445.

Bondada, B.R., M. Romero-Aranda, J.P. Syvertsen, and L.G. Albrigo. 1995. Cytological studies of phytotoxicity induced by foliar-applied urea-nitrogen in Citrus. HortScience 30:879.

Bowman, D.C. and J.L. Paul. 1992. Foliar absorption of urea, ammonium, and nitrate by perennial ryegrass turf. J. Amer. Soc. Hort. Sci. 117:75-79.

Bukovac, M.J. and P.D. Petracek. 1993. Characterizing pesticide and surfactant penetration with isolated plant cuticles. Pesticide Sci. 37:179_ 194.

Cook, J.A. and D. Boynton. 1952. Some factors affecting the absorption of urea by McIntosh apple. Proc. Amer. Soc. Hort. Sci. 59:82-90.

Council for Agricultural Science and Technology. 1985. Agriculture and ground water quality. Council Agr. Sci. Technol. Rpt. 103.

Eckl, K. and H. Gruler. 1980. Phase transitions in plant cuticles. Planta 150:102-113.

Espelie, K.E., R.W. Davis, and P.E. Kolattakudy. 1980. Composition, ultrastructure and function of the cutin- and suberin-containing layers in the leaf, fruit peel, juice-sac and inner seed coat of grapefruit (Citrus paradisi Macf.). Planta 149:498-511.

Ferguson, R.B., D.E. Kissel, J.K. Koelliker, and W. Basel. 1984. Ammonia volatilization from surface-applied urea: Effect of hydrogen ion buffering capacity. Soil Sci. Soc. Amer. J. 48:578-582.

Freeman, B., L.G. Albrigo, and R.H. Biggs. 1979. Ultrastructure and chemistry of cuticular waxes of developing Citrus leaves and fruits. J. Amer. Soc. Hort. Sci. 104:801-808.

Freiberg, S.R. and P. Payne. 1957. Foliar absorption of urea and urease activity in banana plants. Proc. Amer. Soc. Hort. Sci. 69:226-234.

Greene, D.W. and M.J. Bukovac. 1971. Factors influencing the penetration of naphthalenacetamide into leaves of pear (Pyrus communis L.) J. Amer. Soc. Hort. Sci. 96:240-246.

Haas, K. and J. Schönherr. 1979. Composition of soluble cuticular lipids and water permeability of cuticular membranes from Citrus leaves. Planta 146:399-403.

Impey, R.L. and W.W. Jones. 1960. Rate of absorption of urea by intact leaves of Washington Navel orange. Proc. Amer. Soc. Hort. Sci. 76:181-185.

Jeffree, C.E. 1996. Structure and ontogeny of plant cuticles, p. 33-82. In: G. Kerstiens (ed.). Plant cuticles-An integrated functional approach. BIOS Scientific Publishers, Oxford, United Kingdom.

Katoh, M. and K. Matsumoto. 1980. A freeze-drying method for samples substituted with a fifty percent acetonitrile aquatic solution, with metal block for drying. J. Electron Microscopy 29:197-198.

Klein, I. and S.A. Weinbaum. 1985. Foliar application of urea to almond and olive: Leaf retention and kinetics of uptake. J. Plant Nutr. 8:117129.

Knoche, M. and M.J. Bukovac. 1999. Spray application factors and plant growth regulator performance: II. Foliar uptake of gibberellic acid and 2,4-D. Pesticide Sci. 55:166-174.

Knoche, M., N.K. Lownds, and M.J. Bukovac. 1992. Factors affecting the absorption of gibberellin $\mathrm{A}_{3}$ by sour cherry leaves. Crop Protection 11:57-63.

Knoche, M., P.D. Petracek, W.E. Shafer, and M.J. Bukovac. 1994. Urea penetration of isolated tomato fruit cuticles. J. Amer. Soc. Hort. Sci. 119:761-764.

Lea-Cox, J.D. and J.P. Syvertsen. 1995. Nitrogen uptake by Citrus leaves. J. Amer. Soc. Hort. Sci. 120:505-509.

Martin, J.T. and B.E. Juniper. 1970. The cuticles of plants. St. Martin's Press, New York.

Morrison, R.T. and R.N. Boyd. 1974. Organic chemistry. Allyn and Bacon, Inc., Boston.

Norris, R.F. and M.J. Bukovac. 1969. Some physical-kinetic consideration in penetration of naphthaleneacetic acid through isolated pear leaf cuticles. Physiol. Plant. 22:701-712.

Petracek, P.D., R.G. Fader, M. Knoche, and M.J. Bukovac. 1998. Surfactant-enhanced penetration of benzyladenine through isolated tomato fruit cuticular membranes. J. Agr. Food Chem. 46:2346-2352.

Rabe, E. 1994. Yield benefits associated with pre-blossom low-biuret urea sprays on Citrus spp. J. Hort. Sci. 69:495-500.

Reynolds, E.S. 1963. The use of lead citrate at high $\mathrm{pH}$ as an electronopaque stain in electron microscopy. J. Cell Biol. 17:208-212.

Reynolds, C.M. and D.C. Wolf. 1987. Effect of soil moisture and air relative humidity on ammonia volatilization from surface-applied urea. Soil Science 143:144-152.

Schönherr, J. 1976. Water permeability of isolated cuticular membranes: The effect of $\mathrm{pH}$ and cations on diffusion, hydrodynamic permeability and size of pores in the cutin matrix. Planta 128:113-126.

Schönherr, J. and H.W. Schmidt. 1979. Water permeability of plant cuticles. Planta 144:391-400.

Shafer, W.E., R.D. Morse, and M.J. Bukovac. 1988. Effect of $\mathrm{pH}$ and temperature on sorption of auxins by isolated tomato fruit cuticles. HortScience 23:204-206.

Spurr, A.R. 1969. A low-viscocity epoxy resin embedding medium for electron microscopy. J. Ultrastruct. Res. 26:31-43.

Stempak, J.G. and R.T. Ward. 1964. An improved staining method for electron microscopy. J. Cell Biol. 22:697-700.

Wesely, R.W., R.C. Shearman, E.J. Kinbacher, and S.R. Lowry. 1987. Ammonia volatilization from foliar-applied urea on field-grown Kentucky bluegrass. HortScience 22:1278-1280.

Yadav, D.S., V. Kumar, M. Singh, and P.S. Relan. 1987. Effect of temperature and moisture on kinetics of urea hydrolysis and nitrification. Austral. J. Soil Res. 25:185-191.

Yamada, Y., S.H. Wittwer, and M.J. Bukovac. 1964. Penetration of ions through isolated cuticles. Plant Physiol. 39:28-32.

Yamada, Y., S.H. Wittwer, and M.J. Bukovac. 1965. Penetration of organic compounds through isolated cuticular membranes with special reference to ${ }^{14} \mathrm{C}$ urea. Plant Physiol. 40:170-175. 